\title{
Development of Experimental Methods for Study of Gas-Phase Charge-Reversal Charge Transfer Processes of Potential Interest in Smoke Chemistry*
}

by

Nancy J. Jensen and Terry Sumpter

Research Center, Philip Morris, P.O. Box 26583; Richmond,

VA 23261, USA.

\section{SUMMARY}

Gas phase reactions are of fundamental interest in smoke chemistry. Many types of reactions and decompositions have been characterized. However, one type of reaction, the charge transfer process, is very difficult to characterize by conventional means. Methods have been developed using a four sector tandem mass spectrometer for chemical characterization of charge-reversal charge transfer reaction products. This is accomplished by operating two of the sectors of the instrument in the negative ion mode and the other two sectors of the instrument in the positive ion mode with inert gas collision at the interface to facilitate charge transfer. For example if a negatively charged ion generated and selected in MS I is collisionally activated at the interface and the products are analyzed with MS $\Pi$ in the positive ion mode, then only chemical species generated in charge-reversal charge transfer processes of the original parent anion are identified. This technique has been applied to fundamental studies of model compounds including fatty acids, solanesol, sugars and humectants.

\footnotetext{
* Received: 12 December 1993 - accepted: 7. December 1994
}

\section{ZUSAMMENFASSUNG}

Bei der Chemie des Rauches sind Gasphasenreaktionen von grundlegendem Interesse. Viele Reaktions- und Zerfallsmechanismen wurden charakterisiert. Ein Reaktionstyp, der Charge-Transfer-Prozeß, ist jedoch mit konventionellen Methoden nur schwer zu bestimmen. Es wurden Methoden entwickelt, mit Hilfe eines 4-SektorTandemmassenspektrometers Reaktionsprodukte von Elektronendonor/- akzeptorkomplexen chemisch zu charakterisieren. Dies wird erreicht, indem zwei der Sektoren des Systems im 'negative ion mode' und die anderen Sektoren im 'positive ion mode' gefahren werden, wobei eine Kollision mit Inertgas am Einlaß den Charge-Transfer-Prozeß erleichtert. Wenn zum Beispiel ein negativ geladenes Ion, welches im Massenspektrometer I erzeugt und getrennt wurde, durch Kollision am Einlaß aktiviert und im Massenspektrometer II im 'positive ion mode' analysiert wird, werden nur chemische Substanzen nachgewiesen, die durch Charge-TransferProzesse des ursprünglichen Ausgangsanions entstanden sind. Diese Technik wurde bei grundlegenden Studien zu Modellverbindungen wie Fettsäuren, Solanesol, Kohlehydraten und Feuchthaltemitteln angewandt. 


\section{RESUME}

Les réactions de la phase gazeuse jouent un rôle fondamental dans l'analyse chimique de la fumée. Beaucoup de méchanismes de réaction et de décomposition ont été caractérisés. Un type de réaction, le 'Charge-TransferProcess', est difficile à expliquer au moyen de méthodes conventionelles. Des méthodes ont été developpées pour caractériser à l'aide d'un spectromètre de masse tandem à quatre secteurs des produits réactionnels obtenus au moyen d'un système de transfert de charge. Ceci est réalisé en opérant deux secteurs du système sous un mode électronique négatif ('negatif ion mode') et les deux autres secteurs sous un mode électronique positif ('positif ion mode'); à l'interface une collision avec du gas inerte facilite le transfer de charge. Si par exemple un ion négatif, généré et fractionné au moyen du spectromètre de masse I est activé par la collision à l'interface et analysé au moyen du spectromètre de masse II sous un mode électronique positif, ne sont identifiées que les substances chimiques qui étaient générées à partir de l'anion original au moyen du système de transfer de charge. Cette technique a été appliqué aux études fondamentales sur les composés models, comprenant les acides gras, le solanesol, les glucides et les humectants.

\section{INTRODUCTION}

Gas phase reactions are of fundamental interest and importance in smoke chemistry. Many types of reactions and decompositions have been characterized. However one type of reaction, the charge transfer process, is very difficult to characterize. Certainly charged moieties exist in the aerosol associated with smoke and considering the diversity of material in the aerosol, it is quite possible that these types of reactions are occurring.

Mass spectrometry has been shown to be a useful tool for observing charge transfer processes. Typically mass spectral studies revealing charge transfer have involved fundamental studies of specific reaction mechanisms $(1,2)$ and characterization of processes occurring in multistage mass spectral experiments in ion trap mass spectrometers $(3,4)$. Also charge exchange has been used for selective ionization $(5,6)$ and is the operative mechanism for the neutralization step in neutralization reionization experiments (7). Much of the literature to date is related to relatively non polar materials with conventional electron impact used as the initial ionization mode. This form of ionization creates odd electron open-shelled ions which have substantially different reactions and decompositions than closed-shelled ions formed by polar materials. Ionized polar molecules would likely be of greater pertinence in smoke chemistry.

A particularly interesting and challenging form of charge transfer is the so called charge reversal process in which not only is the charge transferred but in the process product ions are created from the original parent which have the opposite polarity of the parent (8-13). The spectra of these unique product ions have been useful both for mechanistic and structural characterization studies. The limited number of reports of this phenomenon reflect that several classes of compounds are capable of such reactions but wide spread investigation has been inhibited by the fact that highly specialized tandem mass spectrometry experiments are required to detect the reverse polarity products.

The primary goal of the present research was to investigate, through the use of model compounds, the propensity of classes of compounds of interest in smoke chemistry to undergo charge reversal reactions and products formed in such processes. Since this is not a routine experiment, it was also necessary to develop instrumentation methods for accomplishing such an analysis using a reverse geometry four sector tandem mass spectrometer.

\section{EXPERIMENTAL}

Stearic, oleic, palmitic and palmitoleic acids and solanesol were obtained from Sigma Chemical Company (St. Louis, $\mathrm{MO}$ ). Other compounds were obtained from Aldrich Chemical Company (Milwaukee, WI).

Mass spectral analyses were performed using a JEOL SX 102/ SX 102 tandem mass spectrometer system. This is a four sector instrument in which both MS I and MS II are double focussing reverse geometry instruments. The instrument is based on ion optics developed by Matsuda and is designed with quadrupole lensing for enhanced transmission and sensitivity (14). The instrument is equipped with two collision cells, one in the first field free region and the second at the interface between MS I and MS II.

For all experiments either positive or negative ion fast atom bombardment (FAB) ionization with xenon at 6 $\mathrm{KeV}$ and $10 \mathrm{~mA}$ emission was used as the ionization mode. Glycerol and propylene glycol samples were deposited neat on the $\mathrm{FAB}$ probe tip for direct probe FAB analysis. Other samples were treated with appropriate matrix and deposited on the $\mathrm{FAB}$ probe tip. Matrices included triethanolamine (TEA) for the acids, glycerol for the sugars, and nitrobenzyl alcohol (NBA) doped with $\mathrm{Li}^{+}$for the solanesol. A cation dopant such as lithium is used because solanesol does not protonate to an appreciable extent under $\mathrm{FAB}$ conditions. Other source conditions included ambient temperature, resolving power of ca. 1000 , and full accelerating voltage of $10 \mathrm{KeV}$.

To observe charge exchange processes the desired parent ion, usually $(M+H)^{+}$or $(M-H)^{-}$ion, was selected by 
fixing the magnet and ESA of MS I to pass only the desired ion, collisionally activating the ion with helium at ca. $75 \%$ beam reduction in the collision cell between MS $I$ and MS II, then scanning MS II in the opposite polarity in a $\mathrm{B} / \mathrm{E}$ linked scan to obtain first generation product ions of the opposite polarity as the parent ion. The only significant difference in this experiment from the conventional tandem product ion experiment is that MS I and MS II are operated simultaneously in opposite polarities. A modest modification of the circuitry of the instrument was required to enable simultaneous operation in this fashion. Spectra were recorded in an accumulation mode by the detector of MS II. Typical acquisition times were 10 minutes per sample and all data were processed using the DA 6000 data system. All spectra shown are raw profile data as no spectral smoothing or background subtraction techniques were applied.

\section{RESULTS}

The instrumental conditions and procedures for performing the charge reversal analysis were established using the FAB desorbed cesium iodide anion of $\mathrm{m} / \mathrm{z}$ of 906 which yielded the positive product ions of $\mathrm{m} / \mathrm{z}$ of 653 , 393 and 133. Since these ions are known cesium iodide cations, the results confirmed that the instrument was indeed functioning to detect the phenomenon of interest. The charge transfer occurred as the result of collision of the selected parent with helium at the interface between MS I and MS II. FAB was selected as the mode for ionization for this and subsequent experiments as it involves the desorption of preformed ions and hence is the ionization choice which is the more realistic analogy to ion formation in the smoke aerosol.

Once proper instrument function had been established, fatty acids, sugars, solanesol, and humectants were examined for their propensity to undergo charge transfer. All demonstrated some capability for such reactions. In general for the compounds studied, negative ions seemed to yield a significant contribution of positive ion products as evidenced by the abundance of product ions and low background in the positive ion product spectrum. Although spectral evidence was obtained for negative ion products from positive ion precursors, the ion abundance as compared to background appeared to be less than for the negative ion cases. The specific results are most interesting and are not necessarily in the realm of conventional mass spectrometry interpretations as outlined by MCLAFFERTY (15).

Fatty Acids. The (M - H) anions of stearic, oleic, linoleic, eladic, palmitic, palmitoleic, palmiteladic, trans-2hexenoic acid, trans-6-heptenoic acid, trans-2-octenoic acid and undecylenic acid were examined for positive product ions. The positive product ion spectra (Figures 1 and 2) for the $\mathrm{C}-18$ and $\mathrm{C}-16$ acids are quite similar to each other, ie. they contain the same series of ions, and are very different from the anion product ion spectra for these acids which are characterized by charge-remote fragmentation $(16,17)$. That these spectra are well defined with unit mass resolution is a function of performing the experiment with a four-sector mass spectrometer.

Palmitic and stearic acid, the saturated acids, yield a series of positive ion clusters whose principal masses are $\mathrm{m} / \mathbf{z}$ of 97, 85, 71, 57, 42 and 29 (Figures 1a and 2a). If one unsaturation is present the predominant series of ions is $2 \mathrm{u}$ less than their counterparts for the saturated acids (Figures $1 b, 2 b$ and $2 c$ ). Since the acids studied are unsaturated at the C-9 position, this implies that the positive ion products are associated with the portion of the molecule distal to the carboxylate and it is implied that the double bond may be associated with directing the product ion formation. The involvement of the double bond is further implicated by the results from the analysis of linoleic acid (Figure 1c). For this acid the ions of $\mathrm{m} / \mathrm{z}$ of 41 and 55 are significant just as they were for the monounsaturated acids but the ion of $\mathrm{m} / \mathrm{z}$ of 67 , which is the base peak, and the ion of $\mathrm{m} / \mathrm{z}$ of 79 are both $2 \mathrm{u}$ lower in mass than the principal ions in the respective clusters for the monounsaturated acids.

Although the evidence implicates the double bond in the formation of the principal series of ions for the unsaturated acids, the fact ion clusters are formed and that saturated acids undergo charge reversal processes indicates multiple fragmentation paths may be involved. The ions of $\mathrm{m} / \mathrm{z}$ of $43,57,71$, and 85 which are the dominant series for the saturated acids most likely correspond to alkyl fragments with 3, 4, 5 and 6 carbons, respectively. This implies, but does not require, they are formed at the distal terminus of the acid. Such species could be formed by a variation of charge-remote fragmentation proposed by WYSOCKI and ROSS who postulated loss of alkyl radicals by homolytic cleavages of the distal portion of the chain of fatty acids (18).

Charge-remote fragmentation, as it was originally observed, is characterized by the apparent loss of neutral alkanes preferentially from the distal portion of longchained compounds which have undergone collisions with a noble gas in an MS/MS experiment (16). The initial mechanism proposed was that the fragmentation proceeds via a 6-membered ring transition state leading to the loss of $\mathrm{H}_{2}$ and neutral alkenes. If a similar mechanism were operative in the change-reversal process, then the positive ion product ions might very likely be associated with the transition state or the proposed alkene products. Indeed the series of ions of $\mathrm{m} / \mathrm{z}$ of $41,55,69$, and 83 reflecting one unsaturation are present in noteworthy abundance in the palmitic and stearic acid spectra. 

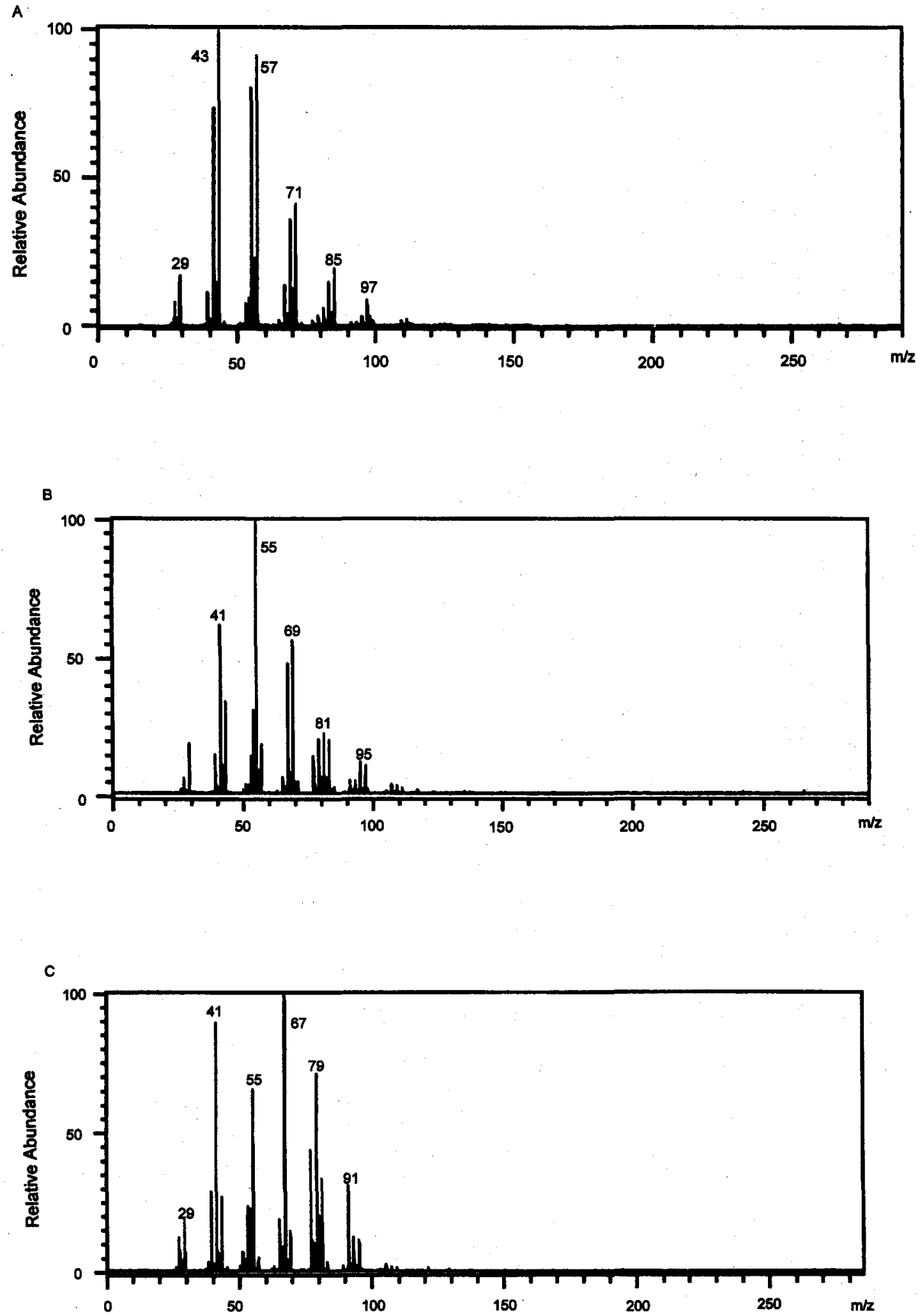

Figure 1.

(a) Positive ion products of the $(\mathrm{M}-\mathrm{H})^{-}$ion of $\mathrm{m} / \mathbf{2}$ of 283 from stearic acid

(b) Positive lon products of the (M-H) lon of $\mathrm{m} / \mathrm{z}$ of 281 from oleic acid

(c) Positive ion products of the (M-H) ion of $\mathrm{m} / \mathrm{z}$ of 279 from linoleic acid 

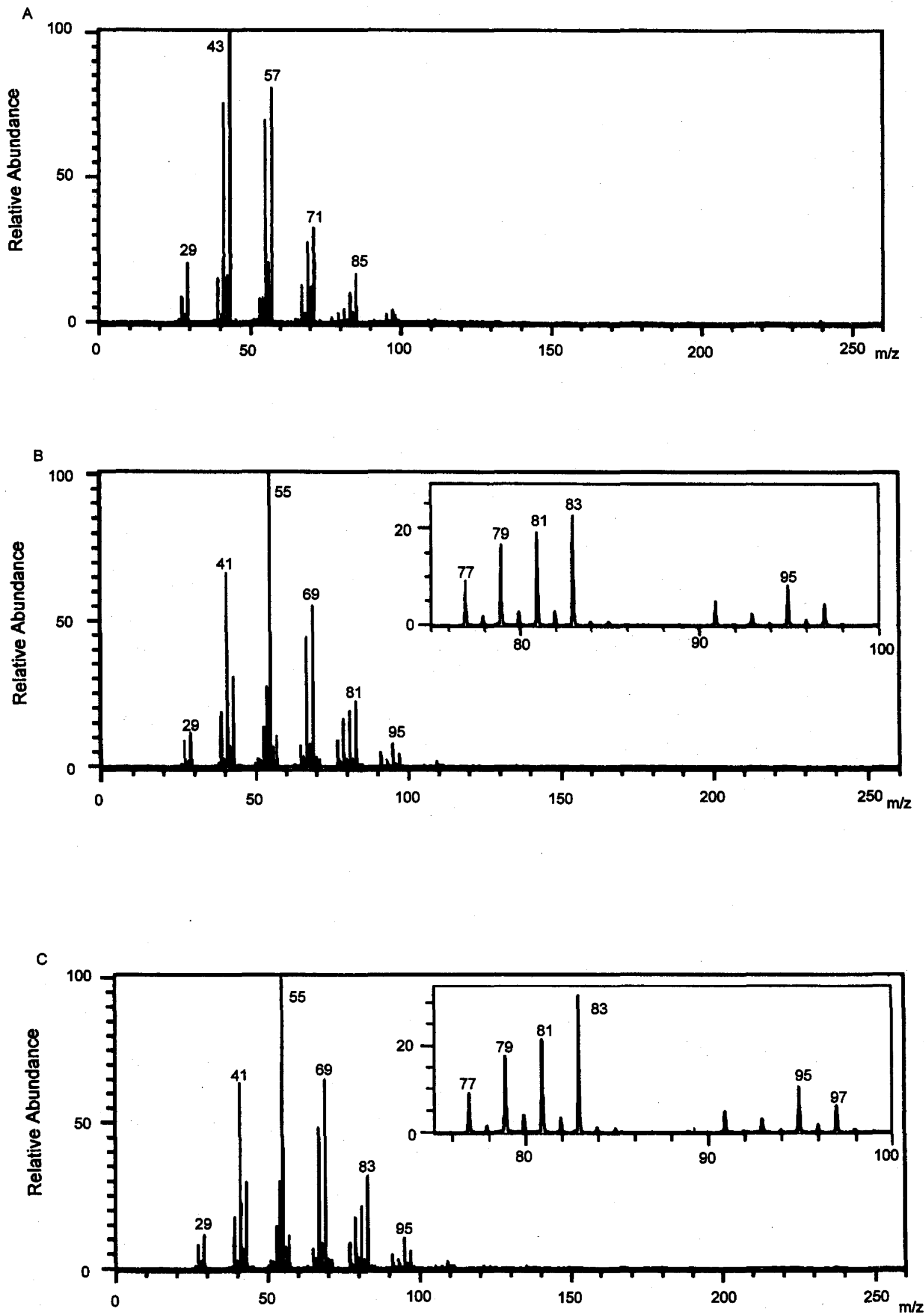

Figure 2.

(a) Positive ion products of the $(M-H)^{-}$ion of $\mathrm{m} / 2$ of 255 from palmitic acid

(b) Positive ion products of the (M-H) ion of $\mathrm{m} / \mathrm{z}$ of 253 from palmitoleic acid (cis isomer)

(c) Positive ion products of the (M-H) ${ }^{-}$ion of $\mathrm{m} / 2$ of 253 from palmiteladic acid (trans isomer) 
Further support of the concept that multiple mechanisms with some similarity to charge remote fragmentation are involved in the charge reversal product formation is provided in recent neutralization-reionization mass spectral analysis of the $(\mathrm{M}-\mathrm{H})^{-}$ion of palmitic acid by WESDEMIOTIS et al. (19). This analysis which permitted ionization of neutral fragmentation products of the collision process yielded the principal series of ions of $\mathrm{m} / \mathrm{z}$ of $27,41,55$ and 69 which correspond to the secondary ion series of ions in the charge reversal experiments with palmitic acid. The neutralization reionization results are consistent with the original mechanism proposed for charge remote fragmentation. However the apparent absence of the higher mass series of ions in the neutralization-reionization experiment indicated that additional processes are involved in the charge reversal reactions.

The shorter-chained monounsaturated fatty acids of trans2-hexanoic, trans-6-heptenoic, trans-2-octenoic and undecylenic acid yielded spectra very similar to those for the $\mathrm{C}-18$ and $\mathrm{C}-16$ monounsaturated acids. The fact that the major ions are the same even though the double bond position is near the carboxylate for the hexenoic and octenoic acids, mid-chain for the C-18 and $\mathrm{C}-16$ acids and in the terminal position for the heptenoic and undecylenic acids implies that the interaction of the double bond with the carbons of the chain is more significant than the relationship of the double bond and the carboxylate to formation of the principal charge-reversal product ions. Formation of a common transition state entity which includes the double-bond and several carbons of the chain might account for the high degree of similarity of charge-reversal product ions for such a range of carboxylate anion parents. Some subtle differences do occur in the spectra but they are minor and need to be evaluated with further experimentation.

Since a double bond, if present, seems to be a dominant factor in directing product ion formation, cis and trans isomers were examined for the monounsaturated $\mathrm{C}-16$ and C-18 acids. As Figure 2 shows and the insets emphasize, no differences were noted in the spectra of the cis trans isomer pair of palmitoleic and palmiteladic acids. However for eladic acid and oleic acid, which have a longer chain after the double bond, subtle differences were noted in the relative abundances of the higher mass ion clusters. Thus unlike the case for the carboxylate anion product ion spectra in which cis and trans isomers may be distinguished from the 4-sector anion product ion spectra, cis trans distinction for monounsaturated acids in charge reversal spectra, if possible, is apparently limited to specific examples (17).

The results from the charge reversal analysis of the fatty acid anions show that charge reversal is not a simple process and that it can not be explained by conventional mass spectrometry interpretations or by simple application of proposed mechanisms for collision processes. However, the fact that the products are formed by collision of preformed ions with neutrals is certainly analogous to processes which might occur in the smoke aerosol and hence the propensity of classes of molecules associated with tobacco and casing chemistry to be involved in these types of reactions is pertinent.

The positive product ion charge reversal spectra of glucose and fructose $(\mathrm{M}-\mathrm{H})^{-}$anions are shown in Figure 3. Although the general appearance of the positive ion product spectra with major clusters of ions below $100 \mathrm{u}$ is like the spectra for the acids, the masses of the ions in the clusters are distinctive for the sugars. The ion of $m / z$ of 31 most likely has the formula of $\mathrm{CH}_{3} \mathrm{O}$ and the ion of $\mathrm{m} / \mathrm{z}$ of 61 may be formally assigned as $\mathrm{C}_{2} \mathrm{H}_{5} \mathrm{O}_{2}$. This is particularly interesting as ions which reflect the losses of $30 \mathrm{u}$ and $60 \mathrm{u}$ are the third and fourth, respectively, most abundant ions in the (M - H) anion product spectrum of the fructose anion. Thus it is possible that the ions of $\mathrm{m} / \mathrm{z}$ of 31 and 61 of the charge reversal spectra are related to these apparent neutral losses of the anion product spectrum. The inset in Figure 3a shows the unit resolution of the product ions and their substantial abundance with respect to background.

Charge-reversal is not limited to positive product ions from anion precursors. Negative ion products may be obtained from positive ion precursors. The $(\mathrm{M}+\mathrm{Li})^{+}$ cation of $\mathrm{m} / \mathrm{z}$ of 637 of solanesol yields charge-reversal anion products which include a number of high mass ions (Figure 4).

This is quite different than the anion parent examples above which principally yield low mass ions. The negative product ion of $\mathrm{m} / \mathrm{z}$ of 627 is most unusual as formation of that ion requires the loss of $10 \mathrm{u}$ from the parent, an unacceptable value in traditional interpretation. However it can be rationalized in this experiment as the loss of $\mathrm{LiH}+\mathrm{H}_{2}$. Certainly the loss of $\mathrm{LiH}$ from the parent cation is plausible and $\mathrm{H}_{2}$ elimination is frequently observed in decompositions of closed shelled anions. The principal positive MS/MS ion products of the $(\mathrm{M}+\mathrm{Li})^{+}$ion for solanesol are a series of ions differing by one terpene unit which may be interpreted as a fingerprint of the entire carbon chain. Figure 4 shows that the charge-reversal anion products do not reflect this fingerprint pattern nor is there an obvious correlation between these anion products and positive ion products. Thus the decomposition pathway for the anion formed by the charge- reversal process from the $(\mathrm{M}+\mathrm{Li})^{+}$parent must be quite different than that for the positive ion products. Previous MS/MS/MS analysis of positive ion second generation positive product ions from the $(\mathrm{M}+$ $\mathrm{Li}^{+}$ion of solanesol has suggested multiple sites of lithium attachment with attachment at the $\mathrm{OH}$ functionality of the solanesol the apparent favored site (20). If the loss of $\mathrm{LiH}$ was more facile at other points of 

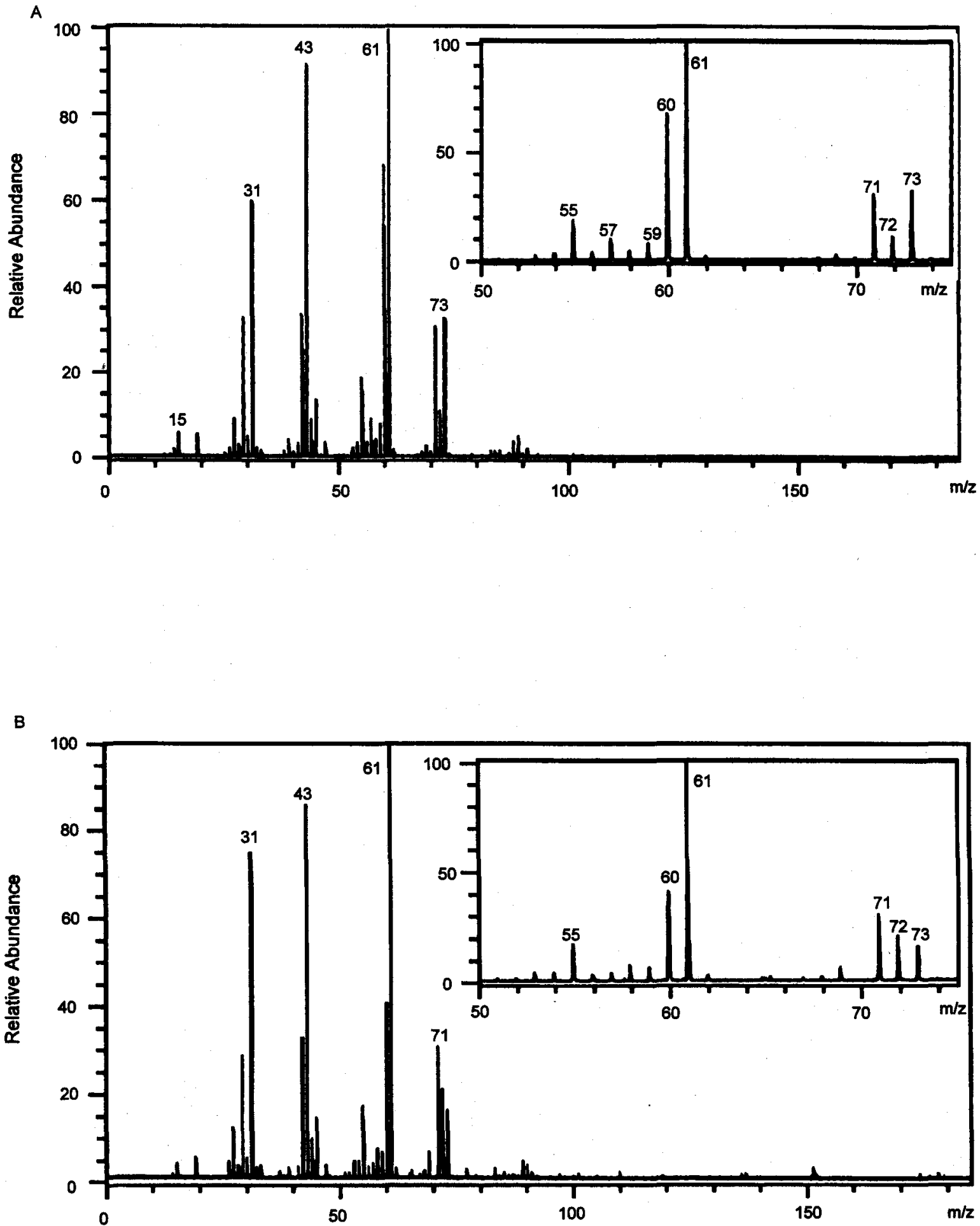

Figure 3.

(a) Positive ion products of the $(M-H)^{-}$ion of $\mathrm{m} / \mathrm{z}$ of 179 from glucose

(b) Positive ion products of the $(M-H)^{-}$ion of $\mathrm{m} / \mathrm{z}$ of 179 from fructose 


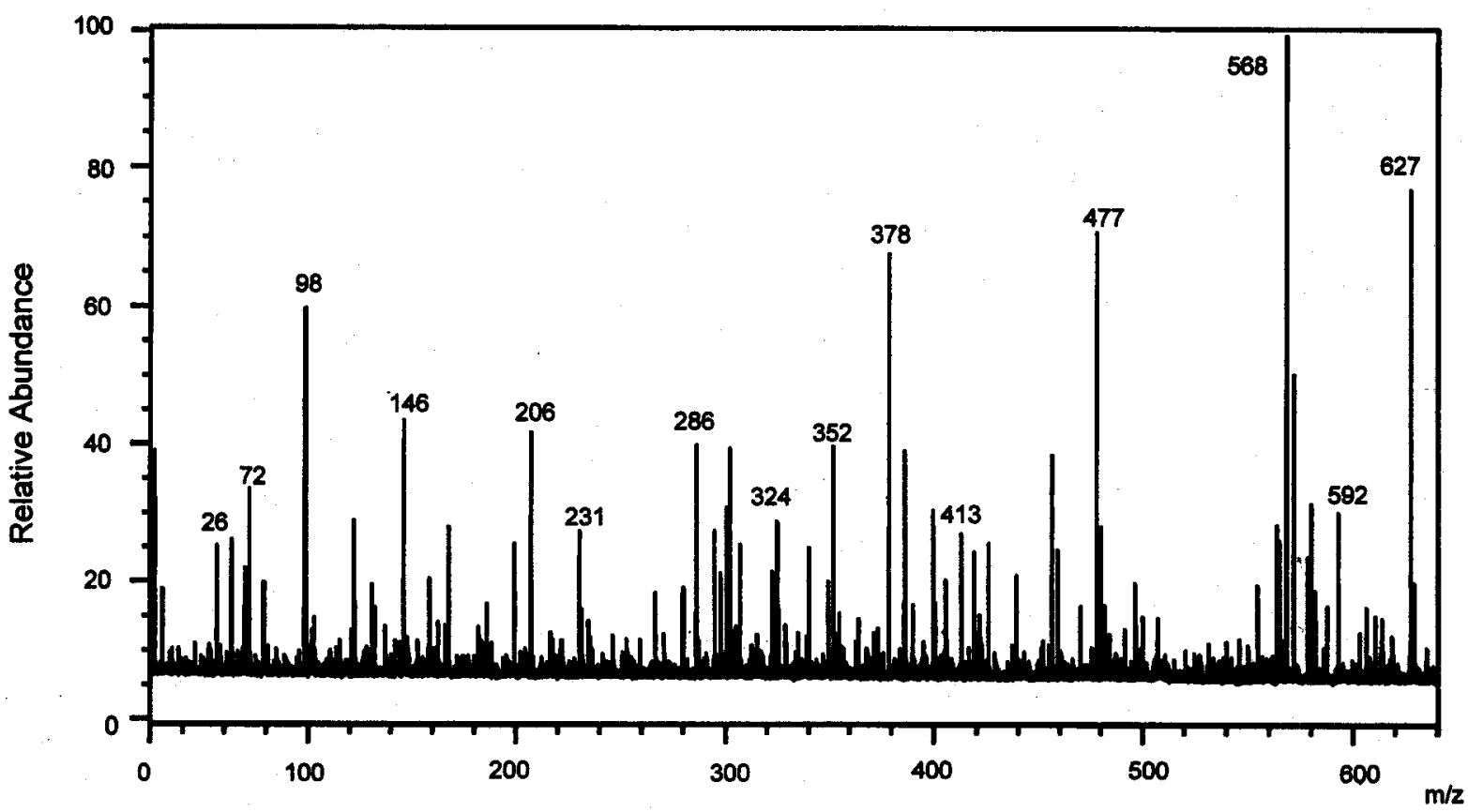

Figure 4.

Negative ion products of the $(M+L i)^{+}$ion of $\mathrm{m} / 2$ of 637 from solanesol.

attachment than the alcohol functionality, then the charge-reversal spectra might be associated with one of the alternative forms of lithiated species which are only minor contributors to the positive ion spectra. Background signal is more apparent in the solanesol spectrum than in the previous examples which suggests that the ion abundances are much less than for the previous examples. This is consistent with the hypothesis of multiple sites of lithium attachment.

The humectants propylene glycol and glycerol are especially interesting candidates for charge reversal analysis as both may be readily desorbed by $\mathrm{FAB}$ as positive or negative ions. As Figure 5 shows the $(M-H)^{-}$anions of both compounds yield positive ion product spectra. The propylene glycol anion of $\mathrm{m} / \mathrm{z}$ of 75 has principal positive product ions of $\mathrm{m} / \mathrm{z}$ of $29,31,44,56$ and 73 while the major positive product ions for glycerol are ions of $\mathrm{m} / \mathrm{z}$ of 29,31 and 43 . The ions of $\mathrm{m} / \mathrm{z}$ of 29 and 31 which are present in both cases are most likely $\mathrm{CHO}$ and $\mathrm{CH}_{3} \mathrm{O}$. The propylene glycol also has prominent positive product ions which are associated with the loss of $\mathrm{H}_{2}$ and most likely the loss of $\left(\mathrm{H}_{2}+\mathrm{OH}\right)$. Apparently the presence of $\mathrm{OH}$ substituents on all of the carbons of glycerol restricts the loss of $\mathrm{H}_{2}$.

The $(\mathrm{M}+\mathrm{H})^{+}$cations of $\mathrm{m} / \mathrm{z}$ of 77 and 93 , respectively, of propylene glycol and glycerol were examined for the formation of negative ion charge-reversal products. Such ions were obtained for propylene glycol but repeated analysis of glycerol yielded no evidence for the presence of any anion products from the positive parent (Figure 6). The ion of $\mathrm{m} / \mathrm{z}$ of 30 which may be formally assigned as $\mathrm{CH}_{2} \mathrm{O}$ and an ion formed by the loss of $\mathrm{H}_{2}$ from the parent were the principal ions of the propylene glycol spectrum. Considering that the $(\mathrm{M}-\mathrm{H})^{-}$anion to positive product charge-reversal data above implies that $\mathrm{H}_{2}$ loss is a facile process for propylene glycol but not glycerol, perhaps the ability to lose $\mathrm{H}_{2}$ is the key factor to initiate formation of the anion products. This would account for the presence of propylene glycol anion products and absence of glycerol products.

\section{SUMMARY}

The propensity of ions to undergo charge-reversal chargetransfer processes can be examined in a facile manner using a four sector tandem mass spectrometer with MS I and MS II operated in reverse polarities and collision with helium gas at the interface between MS I and MS II. That a number of compounds of interest in smoke chemistry can undergo such reactions as established in this work is significant. While it may be argued that the reactions were 

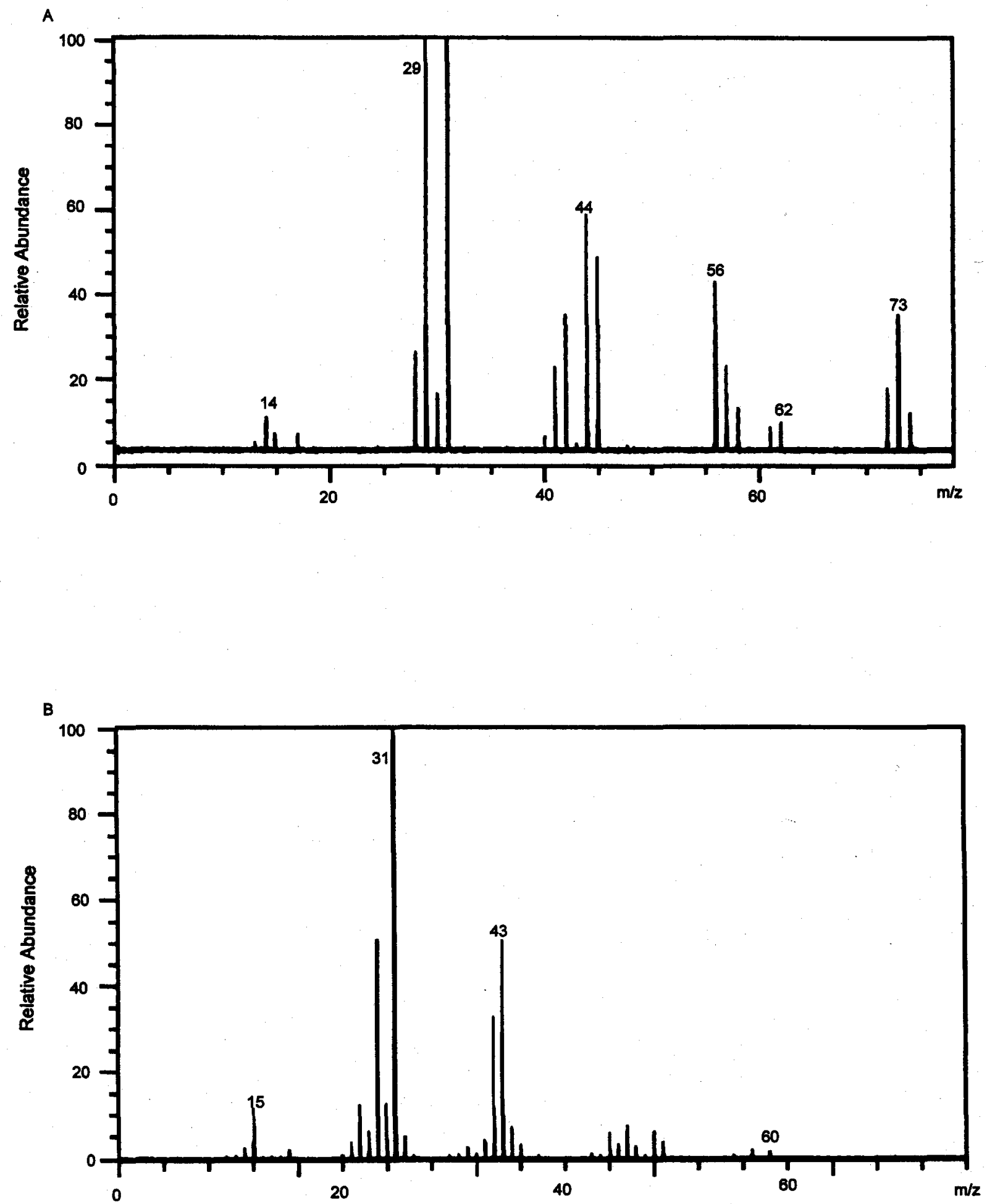

Figure 5.

(a) Positive ion products of the $(\mathrm{M}-\mathrm{H})^{-}$lon of $\mathrm{m} / \mathrm{z}$ of 75 from propylene glycol

(b) Positive ion products of the $(M-H)^{-}$ion of $\mathrm{m} / \mathrm{z}$ of 91 from glycerol 

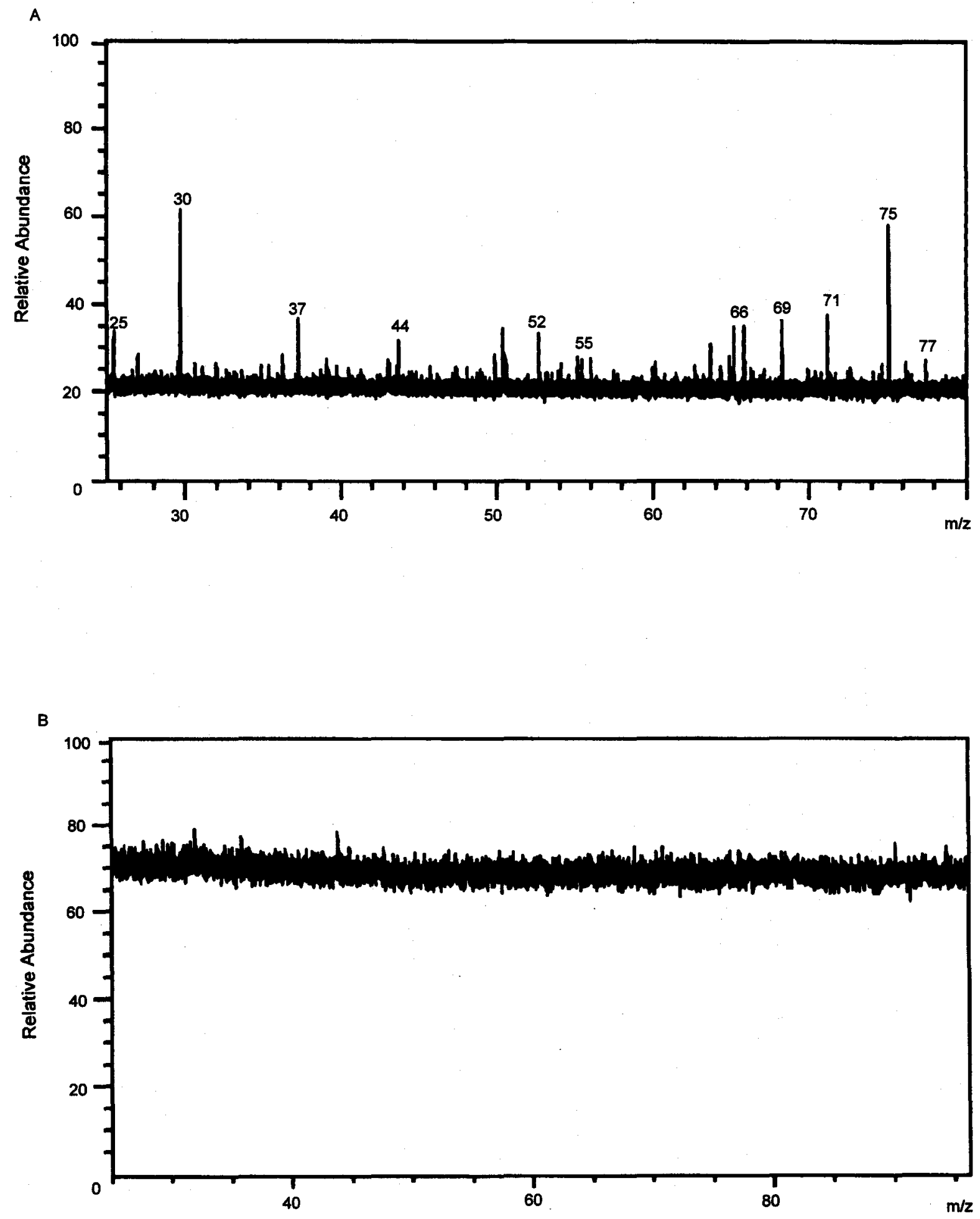

Figure 6.

(a) Negative ion products of the $(\mathrm{M}+\mathrm{H})^{+}$ion of $\mathrm{m} / \mathrm{z}$ of 77 from propylene glycol

(b) Negative ion products of the $(M+H)^{+}$ion of $\mathrm{m} / \mathrm{z}$ of 93 from glycerol 
observed in a mass spectrometer, the fact that all parent ions examined were closed-shell ions which were desorbed intact and were not generated in an electron beam does make them arialogous to ionized species that would be present in smoke aersol. Certainly the charge reversal data provides unique information and although the processes that are occurring can not be fully explained at present, consideration of these processes does provide the potential for new insights into the complex reactions associated with smoke chemistry.

\section{REFERENCES}

1. Hudson, C.E., Ahmed, M.S., Olivella, S., Giam, C.S., and D.J. McAdoo: The arrier to methane elimination from ionized butan-2-one: theory and experiment; Org. Mass Spectrom. 27 (1992) 435-438.

2. Usypchuk, L.L., Harrison, A.G., and J. Wang: Reactive collisions in quadrupole cells, part $\mathrm{I}$, reaction of $\mathrm{CH}_{3} \mathrm{NH}_{2}{ }^{+}$buI. With the isomeric butenes and pentenes; Org. Mass Spectrom. 27 (1992) 777-782.

3. Louris, J.N., Brodbelt-Lustig, J.S., Cooks, R.G., Glish, G.L., Van Berkel, G.J., and S.A. McLuckey: Ion isolation and sequential stages of mass spectrometry in a quadrupole ion trap mass spectrometer; Int. J. Mass Spectrom. Ion Processes 96 (1990) 117137.

4. Basic, C., Eyler, J.R., and R.A. Yost: Probing trapped ion energies via ion-molecule reaction kinetics: quadrupole ion trap mass spectrometry; J. Am. Soc. Mass Spectrom. 3 (1992) 716-726.

5. Chester, T.L., Pinkston, J.D., Innis, D.P., and J.D. Bowling: Separation, detection, and identification of inositol triphosphate and phytic acid derivatives by supercritical fluid chromatography and SFC-mass spectrometry; J. Microcolumn Sep. 1 (1989) 182-189.

6. Huang, S.: Obtaining structrural information on perfluorocarbons by mass spectrometry II. Charge exchange method; Org. Mass Spectrom. 24 (1989) 1065-1071.

7. Hop, C.E.C.A., and J.L. Holmes: Neutralizationreionization mass spectrometry: efficiency of the charge-exchange process; Org. Mass Spectrom. 26 (1991) 476-480.

8. Zappey, H.W., Ingemann, S., and N.M.M. Nibbering: Gas-phase ion-molecule reactions of the methoxy cation $\left(\mathrm{CH}_{3} \mathrm{O}^{+}\right)$; J. Am. Soc. Mass Spectrom. 3 (1992) 515-517.

9. Leyh, B., and H. Wankenne: Influence of electronic excitation in the charge reversal of halogenated cations; Int. J. Mass spectrm. Ion Processes 107 (1991) 453-474.
10. Kostka, S., Schroeder, D., and H. Schwarz: Experimental evidence for the conservation of an intact carbon skeleton and the intermediacy of a solvated hydride ion in the unimolecular dehydrogenation of the norborneol alkoxides in the gas phase; Int. J. Mass Spectrom. Ion Processes 117 (1992) 15-22.

11. Zhang, M.Y., Wesdemiotis, C., Marchetti, M. Danis, P.O., Ray, J.C., Carpenter, B.K., and F. McLafferty: Characterization of four $\mathrm{C}_{4} \mathrm{H}_{4}$ molecules and cations by neutralization-reionization mass spectrometry; J. Am. Chem. Soc. 111 (1989) 8341-8346.

12. Surig, T., and H.-F. Grutzmacher: Charge-reversal mass spectra of enolate ions of some open-chain and cyclic ketones for structure identification; Org. Mass Spectrom. 25 (1990) 446-452.

13. Tomer, K.B.: Charge-remote and charge-reversal competition; Org. Mass Spectrom. 24 (1989) 969-972.

14. Matsuda, H.: High-resolution high transmission mass spectrometer; Int. J. Mass Spectrom. Ion Processes 66 (1985) 209-215.

15. McLafferty, F.: Interpretations of mass spectra, 3rd ed.; University Science Books, Mill Valley, CA, 1980.

16. Jensen, N. J., Tomer, K.B., and M. L. Gross: Gasphase ion decompositions occurring remote to the charge site; J. Am. Chem. Soc. 107 (1985) 1863-1868.

17. Jensen, N. J., Lam, K., Cody, R.B., and J. Tamura: Evidence for distiction of cis and trans isomers of mono-unsaturated fatty acids by fast-atom bombardment tandem mass spectrometry; Rapid Com. in Mass Spectrom. 4 (1990), 239-241.

18. Wysocki, V., and M. Ross: Charge-remote fragmentation of gas-phase ions: mechanistic and energetic considerations in the dissociation of long-chain functionalized alkanes and alkenes; Int. J. Mass Spectrom. Ion Proc. 104 (1991) 179-211.

19. Cordero, M.M., and C. Westodemiotis: The neutral products from the remote site fragmentation of fatty acid derivatives; Proceedings of the Am Soc. for Mass Spectrom. May 30 - June 4, 1993, San Francisco.

20. Jensen, N.J., and T. Sumpter: Specific Structural Analysis of Solanesol and Related Compounds by Fast Atom Bombardment and Tandem Mass Spectrometry; Beitr. Tabakforsch. Int. 16 (1995) 85 - 93.

\section{Authors' address}

Philipp Morris Research Center,

P. O. Box 26583,

Richmond, Virginia,

23261-6583, USA. 